\title{
Effects of Functionalized Kraft Lignin Incorporation on Polypropylene Surface Energy and Practical Adhesion
}

\author{
Manuel Patricio da Silva Bisneto ${ }^{1} \mathbb{D}$, Julia Rocha Gouveia ${ }^{1} \mathbb{D}$, Leonardo Dalseno Antonino ${ }^{1}$, Lara Basílio Tavares ${ }^{1}$, \\ Nathalie Minako Ito ${ }^{1}$ and Demetrio Jackson dos Santos $1,2, *$ \\ 1 Nanoscience and Advanced Materials Graduate Program (PPG-Nano), Federal University of ABC (UFABC), \\ Santo Andre 09210-580, Brazil; manuel.bisneto@ufabc.edu.br (M.P.d.S.B.); juliargouveia@gmail.com (J.R.G.); \\ leonardoantonino@hotmail.com (L.D.A.); lara.btavares@hotmail.com (L.B.T.); \\ nathalie.minako@gmail.com (N.M.I.) \\ 2 Center of Engineering, Modeling and Applied Social Sciences, Federal University of ABC (UFABC), \\ Santo Andre 09210-580, Brazil \\ * Correspondence: demetrio.santos@ufabc.edu.br
}

Citation: Bisneto, M.P.d.S.; Gouveia, J.R.; Antonino, L.D.; Tavares, L.B.; Ito, N.M.; dos Santos, D.J. Effects of Functionalized Kraft Lignin Incorporation on Polypropylene Surface Energy and Practical Adhesion. Polymers 2022, 14, 999. https://doi.org/10.3390/ polym14050999

Academic Editors: John Vakros, Evroula Hapeshi, Catia Cannilla and Giuseppe Bonura

Received: 17 January 2022

Accepted: 27 February 2022

Published: 1 March 2022

Publisher's Note: MDPI stays neutral with regard to jurisdictional claims in published maps and institutional affiliations.

Copyright: (C) 2022 by the authors. Licensee MDPI, Basel, Switzerland. This article is an open access article distributed under the terms and conditions of the Creative Commons Attribution (CC BY) license (https:// creativecommons.org/licenses/by/ $4.0 /$ )

\begin{abstract}
Polypropylene (PP) is a multifunctional and widely applied polymer. Nevertheless, its low energy surface and poor adhesion are well-known and might impair some prospective applications. Aiming to overcome these limitations, PP composites can be applied as a tool to enhance PP surface energy and then increase its practical adhesion. In this work, Kraft lignin (KL) was chemically modified and blended with PP. In short, KL was hydroxypropylated and further reacted with acetic anhydride (A-oxi-KL) or maleic anhydride (M-oxi-KL). Lignin modifications were confirmed by Fourier transform infrared spectroscopy (FTIR), differential scanning calorimetry (DSC), and thermogravimetric analysis (TGA). PP-composites with different lignin contents, as well as pristine $\mathrm{PP}$, were characterized in terms of their thermal behavior, morphology, surface energy, and practical adhesion by DSC, scanning electron microscopy (SEM), contact angle measurement, and peeling tests, respectively. Lignin incorporation did not affect the PP degree of crystallization. The lignin modifications led to a better compatibility with the PP matrix and surface energies up to $86 \%$ higher than neat PP. Increases of up to $66 \%$ in the peel strength were verified. Composites with M-oxiKL showed the best adhesion performance, confirming the lignin functionalization is an efficient approach to improve the practical adhesion of PP films.
\end{abstract}

Keywords: lignin; surface energy; wettability; practical adhesion

\section{Introduction}

Polypropylene (PP) is a multifunctional and low-cost polymer widely used in industrial applications. Nevertheless, it presents low surface energy because of its non-polar chemically stable structure, which leads to adhesion hindrance, such as coating failures or flexible laminated layers delamination. Polymer blending can be used as a strategy to alter the wettability of PP and increase the strength of PP adhesive joints. The combination of PP with renewable resource materials has been intensively investigated as a promising approach to reduce petroleum-based dependency, hence collaborating to a reduced environmental impact. The wettability and surface roughness of polypropylene can be improved when filled with wood flour [1]. Cellulose, potato starch, and chitosan were also reacted with PP for membranes application, and the new materials changed their hydrophobicity, besides mechanical properties improvements [2].

Another strategy arises from a remarkable sustainable raw material that has been successfully applied as high-added-value for polymer blends and composites. Lignin, the second most abundant biopolymer on earth, can be found in all vascular plants and is an amorphous phenolic polymer, consisting of three main phenylpropane units (guaiacyl, synrigyl, and p-hidroxyphenyl) [3], that must be isolated from the other components, cellulose 
and hemicellulose, to be used as a technical grade [4]. Among the extraction methods, Kraft pulping, from pulp and paper industry, is the predominant process for technical lignin obtention, which is then commonly referred to as Kraft lignin [5]. In general, lignin has several advantages to be used. It is low cost, widely available, eco-friendly, non-edible, and compostable material. Its structure is composed of many different functional moieties, including aromatic rings, aliphatic and phenolic hydroxyls, carboxyls, and methoxy groups. These groups confer attractive properties, such as high mechanical stiffness, antioxidant behavior, UV absorption, thermal stability, and hydrophilization character [5-7]. The use of lignin in the PP matrix has been widely reported in the literature. Its hindered phenolic structure confers thermal oxidative resistance and has been a promising green substituent to synthetic stabilizers [8,9]. Mechanical properties and thermal stability were also improved by adding lignin [10-12].

Although encouraging results have been reported, the incorporation of lignin in a PPmatrix is not a straightforward task due to the poor compatibility that severely compromises the mechanical properties. Lignin presents difficulties in the thermoplastic molding process because of its indefinite thermal transition temperature [13]. The modification of lignin can overcome this limitation. According to Hui Li et al. [14], lignin modification is classified by two main approaches: i. Fragmentation or depolymerization into reduced molecular weight and highly functional products for further utilization as a reagent, ii. Chemical modification to introduce new reactive sites in order to optimize its structure for a specific application or desired property. Moreover, lignin chemical modification can improve its dispersion in hydrophobic polymer matrices by lowering its glass-transition temperature, which can reduce the final material brittleness while achieving higher surface energy and adhesion [7].

In this work, modified Kraft lignin was applied for the first time as an adhesion promoter for a PP matrix. The lignin was first hydroxypropylated and further esterified via two different routes in order to reduce lignin's $T_{g}$, thus promoting thermal processing, and enhancing the compatibility between it and the PP matrix. The chemical modifications were confirmed by Fourier transform infrared spectroscopy-attenuated total reflectance (FTIRATR), differential scanning calorimetry (DSC), and thermogravimetric analysis (TGA). The variation in wettability and surface energy of the PP-lignin composites were investigated. Additionally, the effect of modified Kraft lignin on the thermal properties of the composites was also explored. Finally, flexible laminated films of PP and PP-lignin composites were formed by bonding to aluminized biaxially oriented polypropylene (BOPP), and the practical adhesion was evaluated by the peeling test. The chemical modification showed a positive effect on PP surface energy and proved to be a good strategy for increasing the compatibility between PP and lignin and promoting the adhesion of this polymer.

\section{Materials and Methods}

\subsection{Materials}

Isotactic polypropylene (iPP) was supplied by Braskem (Triunfo/Brazil), with a density of $0.905 \mathrm{~g} / \mathrm{cm}^{3}$ and labeled as H503HS. Kraft lignin from eucalyptus (hardwood) was kindly supplied by Suzano Papel e Celulose (Limeira/Brazil). According to the supplier, KL has $\mathrm{pH} 8.1,92.5 \%$ solid content, and $10 \%$ ash content. The employed adhesive was a bicomponent polyurethane (PU) from Loctite, composed of the Liofol LA 9526 CP-22 adhesive and its methylene diphenyl diisocyanate (MDI) LA 6145. Propylene oxide, acetic anhydride, maleic anhydride, acetone, diiodomethane, and potassium hydroxide were purchased from Sigma-Aldrich (São Paulo, Brazil) and used as received.

\subsection{Modification of $K L$}

First, KL was hydroxypropylated, aiming to convert aromatic $\mathrm{OH}$ groups into aliphatic ones and to increase lignin reactivity, following the methodology presented by Garcia et al. [15]. The hydroxypropylation reaction is represented in Figure 1a. Initially, $60 \mathrm{~g}$ of $\mathrm{KL}$ were solubilized in a $\mathrm{KOH}$ solution $(2.5 \mathrm{M})$. After homogenization, $60 \mathrm{~mL}$ of propylene 
oxide (PO) were dropwise added to the solution. The mixture was kept at constant $\mathrm{pH}$ (11) and under stirring at $40{ }^{\circ} \mathrm{C}$ for $1 \mathrm{~h}$. Afterward, the mixture was cooled to room temperature and rested for $24 \mathrm{~h}$. At last, hydroxypropylated lignin was precipitated at $\mathrm{pH} 2.5$ using an $\mathrm{HCl}$ solution. The precipitated solid was vacuum-filtrated and washed with deionized water five times. Once hydroxypropylated, the modified KL (Oxy-KL) was reacted with maleic anhydride (MA) or acetic anhydride (AA). The esterification reaction with MA, which is presented in Figure 1b, was carried out according to [16]. The Oxy-KL was immersed in a 10\% solution of MA in acetone with a ratio of 1:20 (w/v). Afterward, it was heated at reflux temperature $\left(60 \pm 2{ }^{\circ} \mathrm{C}\right)$ for $7 \mathrm{~h}$ under a magnetic stirrer in a reactor vessel. At the end of the reaction, the reactive mixture was evaporated to remove the excess acetone. The product was then vacuum-filtered and washed five times with distilled water. On the other hand, the acetylation with AA of Oxy-KL (see Figure 1c) was based on Monteil-Rivera et al. [17]. A total of $50 \mathrm{mg}$ Oxy-KL was solubilized in $100 \mathrm{~mL}$ of AA. The mixture was kept at $60^{\circ} \mathrm{C}$, under magnetic stirring for $24 \mathrm{~h}$. After this time, the mixture was then poured into distilled water $(500 \mathrm{~mL})$ and stirred for $2 \mathrm{~h}$. The precipitated solid was vacuum filtered, washed five times with distilled water, and dried at $60{ }^{\circ} \mathrm{C}$ for $24 \mathrm{~h}$.

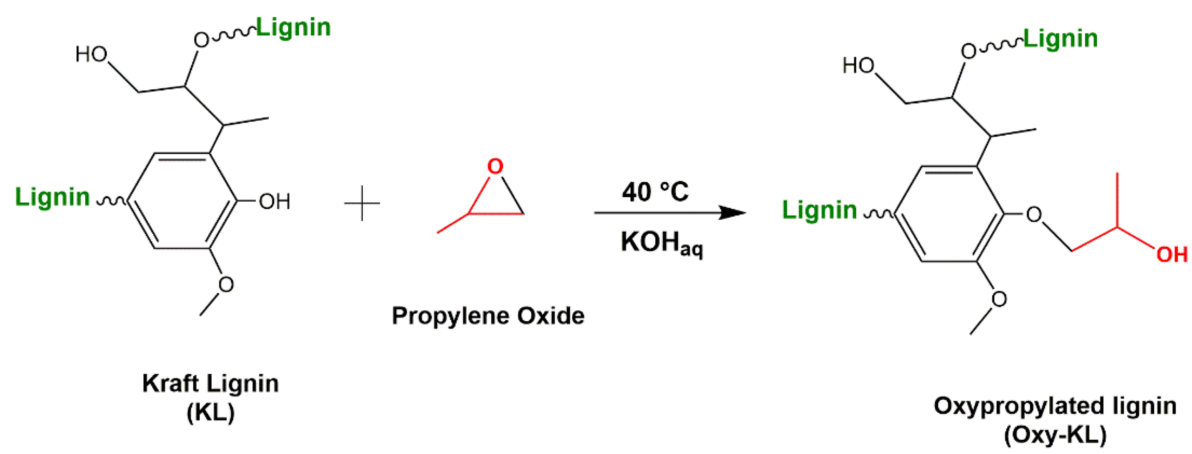

(a)

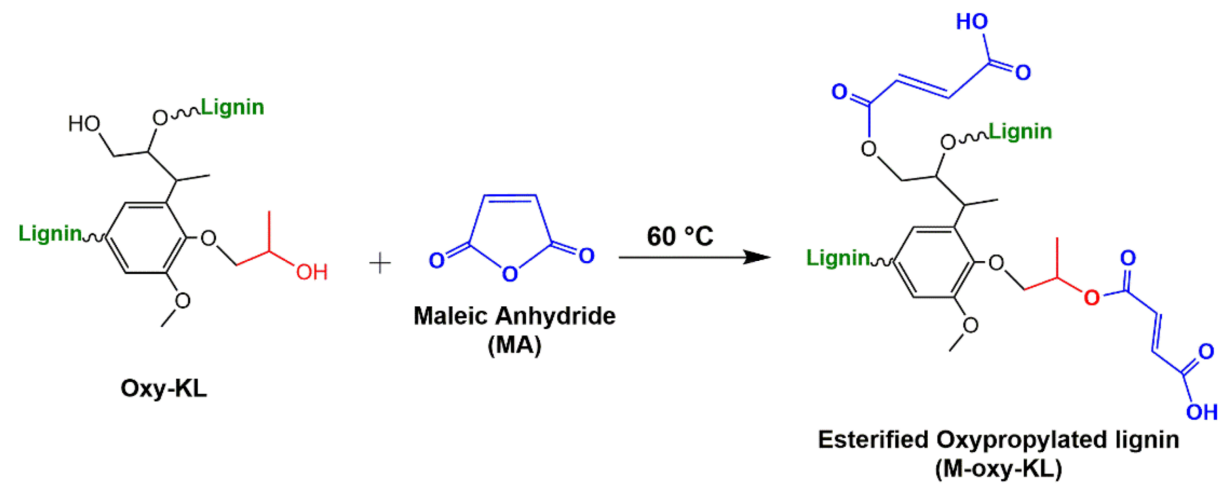

(b)

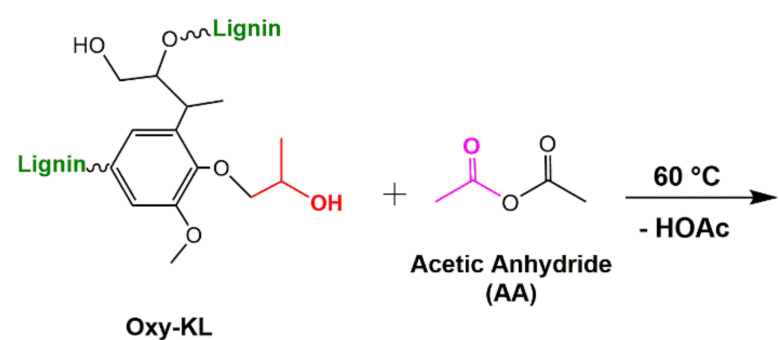

(c)

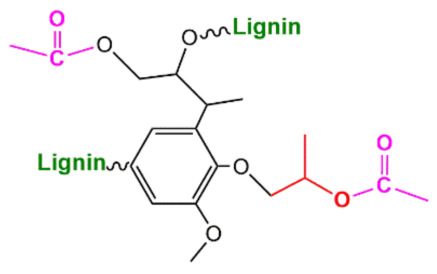

Acetylated Oxypropylated lignin (A-oxy-KL)

Figure 1. Chemical reactions employed in the lignin modification: (a) Hydroxypropylation with propylene oxide; (b) Esterification with maleic anhydride; and (c) Acetylation with acetic anhydride. 


\subsection{Lignins Characterization}

2.3.1. Fourier Transform Infrared Spectroscopy-Attenuated Total Reflectance (FTIR-ATR)

Fourier transform infrared spectroscopy-attenuated total reflectance (FTIR-ATR) was performed on a Spectrum Two (Perkin Elmer, Waltham, MA, USA) instrument to investigate differences between the chemical state of modified and pristine lignin. Spectra were recorded between 3800 and $600 \mathrm{~cm}^{-1}$ with 32 scans and a resolution of $4 \mathrm{~cm}^{-1}$ at room temperature in air.

\subsubsection{Thermogravimetric Analysis}

TGA analyses were performed on a Mettler Toledo TGA. Ca. $8 \mathrm{mg}$ of each sample was weighed and then placed onto the balance of the instrument. The samples were heated from 40 to $550{ }^{\circ} \mathrm{C}$ at a heating rate of $10{ }^{\circ} \mathrm{C} \mathrm{min}-1$ in a nitrogen atmosphere.

\subsubsection{Differential Scanning Calorimetry (DSC)}

DSC analysis was carried out on Mettler Toledo DSC1 Star equipment. Approximately $8 \mathrm{mg}$ of each sample was weighed in an alumina pinhole hermetic lid pan and then placed onto the DSC cavity. The samples were heated from 25 to $200{ }^{\circ} \mathrm{C}$ at $10^{\circ} \mathrm{C} \mathrm{min}{ }^{-1}$, and then cooled down to $25^{\circ} \mathrm{C}$ at the same rate to erase the thermal history. Then, the samples were reheated up to $200{ }^{\circ} \mathrm{C}$ at $10^{\circ} \mathrm{C} \mathrm{min}^{-1}$ and the heat flow was recorded for analysis.

\subsection{Composites Preparation}

First, samples of PP and KL and its derivatives (A-oxy-KL and M-oxy-KL) were ovendried at $70{ }^{\circ} \mathrm{C}$ for $24 \mathrm{~h}$. PP-composites, as well pristine PP, were prepared in a twin-screw extruder (Coperion, Stuttgart, Germany), by adding KL, A-oxy-KL, and M-oxy-KL to PP in different concentrations $(1.0,2.5$, and $5.0 \mathrm{wt} \%)$, as presented in Table 1 . The mixtures were carried out separately using a screw speed of $450 \mathrm{rpm}$, between 160 and $210{ }^{\circ} \mathrm{C}$ (from the feed to die) in nine-barrel temperature zones for $3 \mathrm{~min}$. The extruder had a screw diameter of $20 \mathrm{~mm}$ and a length-to-diameter ratio $\mathrm{L} / \mathrm{D}=40$. Then, from the resulting extruded lignin-PP granules, films about $0.3 \mathrm{~mm}$ thick were obtained by compression molding at $200{ }^{\circ} \mathrm{C}$ for $3 \mathrm{~min}$ at $4 \mathrm{kgf} . \mathrm{cm}^{-2}$ pressure for further peeling tests.

Table 1. Sample nomenclatures and compositions.

\begin{tabular}{ccccc}
\hline Name & PP (\%) & KL (\%) & A-oxy-KL (\%) & M-oxy-KL (\%) \\
\hline PP & 100 & - & - & - \\
PP_KL_1 & 99 & 1 & - & - \\
PP_KL_2.5 & 97.5 & 2.5 & - & - \\
PP_KL_5 & 95 & 5.0 & - & - \\
PP_A_Oxi_KL_1 & 99 & - & 1 & - \\
PP_A_Oxi_KL_2.5 & 97.5 & - & 2.5 & - \\
PP_A_Oxi_KL_5 & 95 & - & 5.0 & 1 \\
PP_M_Oxi_KL_1 & 99 & - & - & 2.5 \\
PP_M_Oxi_KL_2.5 & 97.5 & - & - & 5.0 \\
PP_M_Oxi_KL_5 & 95 & - & - &
\end{tabular}

\subsection{Composites Characterization}

\subsubsection{Differential Scanning Calorimetry (DSC)}

DSC analysis was carried out on Mettler Toledo DSC1 Star equipment. Approximately $8 \mathrm{mg}$ of each composite was weighed in an alumina pinhole hermetic lid pan and then placed onto the DSC cavity. The samples were heated from 25 to $200{ }^{\circ} \mathrm{C}$ at $10{ }^{\circ} \mathrm{C} \mathrm{min}{ }^{-1}$, and then cooled down to $-25^{\circ} \mathrm{C}$ at the same rate. Then, the samples were reheated up to $200{ }^{\circ} \mathrm{C}$ at $10^{\circ} \mathrm{C} \mathrm{min}^{-1}$, and the heat flow was recorded for analysis. The glass transition temperature $\left(\mathrm{T}_{\mathrm{g}}\right)$ and the melting temperature $\left(\mathrm{T}_{\mathrm{m}}\right)$ were obtained from the 2 nd heating scan, while the crystallization temperature $\left(T_{c}\right)$ was obtained from the cooling scan. The 
effect of lignin inclusion on the morphology of the composites was also investigated by means of the crystallization degree that was calculated from Equation (1):

$$
\chi(\%)=\frac{\Delta H_{m}}{\Delta H_{m}^{0}} \times \frac{1}{f} \times 100
$$

where $\chi(\%)$ is the crystallization degree, $\Delta H_{m}$ is the enthalpy of fusion of the several composites as well as pristine PP, $\Delta H_{m}^{0}$ is the enthalpy of fusion of $100 \%$ crystalline PP $(207 \mathrm{~J} / \mathrm{g})[18]$, and $f$ is the PP fraction of the composite's composition.

\subsubsection{Scanning Electron Microscopy (SEM)}

Specimens were manually cut for SEM analysis, aiming to investigate the crosssectional morphology and to determine whether phase separation occurred between lignins and PP. For this purpose, samples with the highest lignin amount ( $5 \mathrm{wt} \%$ ) were used. Micrographs were obtained on a Jeol 6460LV scanning electron microscope with $25 \mathrm{kV}$ of accelerating voltage. The specimens were placed on the SEM sample holder and coated with a thin film of gold $(\sim 10 \mathrm{~nm})$.

\subsubsection{Surface Energy}

The solid surface free energy $\left(\gamma_{S}\right)$ was calculated by Young's equation for the equilibrium condition at a solid-liquid interface (Equation (2)), using the contact angle ( $\theta$ ) of a liquid with known surface tension and the solid-liquid interfacial energy $\left(\gamma_{S L}\right)$.

$$
\gamma_{L} \cos \theta=\gamma_{S}-\gamma_{S L}
$$

We used Fowkes model (Equation (3)) for the interfacial free energy between two phases to estimate $\gamma_{S L}$, by combining both polar and dispersive interactions between the solid and liquid surfaces. In this equation, $\gamma_{s}^{d}$ and $\gamma_{s}^{p}$ are the dispersive and polar components of the surface free energy, respectively, and $\gamma_{l}^{d}$ and $\gamma_{l}^{p}$ are the dispersive and polar components of the liquid surface tension, respectively.

$$
\gamma_{S L}=\gamma_{S}+\gamma_{L}-2 \sqrt{\gamma_{S}^{d} \gamma_{L}^{d}}-2 \sqrt{\gamma_{S}^{p} \gamma_{L}^{p}}
$$

Merging both Folke's (Equation (2)) and Young's (Equation (1)) equations, one can calculate $\gamma_{s}^{d}$ and $\gamma_{s}^{p}$ by obtaining the contact angle between the surface and at least two different liquids with known surface tension components.

In this study, the surface energies were determined from contact angle measurements using both distilled water and diiodomethane as liquids. The contact angle was measured by the sessile drop method with a Contact Angle Analyzer (Phoenix 300). The test drop volume was $0.015 \mu \mathrm{L}$, and the measurement was repeated five times for each liquid. The surface tension components of each liquid are shown in Table 2.

Table 2. Surface tension energy of the test liquids [7].

\begin{tabular}{ccc}
\hline Surface Tension & Water & Diiodomethane \\
\hline Total $(\mathrm{mN} / \mathrm{m})$ & 72.8 & 50.8 \\
Polar $(\mathrm{mN} / \mathrm{m})$ & 51.0 & 0 \\
Disperse $(\mathrm{mN} / \mathrm{m})$ & 21.8 & 50.8 \\
\hline
\end{tabular}

\subsubsection{Practical Adhesion}

\section{Lamination Process}

The lamination process was performed manually according to the methodology employed by Tavares et al. [19]. PP and PP-lignin films were cut into $14 \times 28 \mathrm{~cm}$ segments using a template. PU adhesive, which was a stoichiometric mixture of diisocyanate and biopolyol, was dissolved in ethyl acetate at a mass proportion of 50\%. Polymeric films were 
immobilized on a flat surface for adhesive application. PU adhesive $(2 \mathrm{~mL})$ was applied onto the immobilized film using a $10 \mu \mathrm{m}$ spiral lamination roller, without interruption, at constant speed and pressure. PP and PP-lignin films coated with PU were submitted to heating for ethyl acetate releasing $\left(15 \mathrm{~min}\right.$ at $\left.50{ }^{\circ} \mathrm{C}\right)$. Then, an aluminized bioriented polypropylene (BOPP) layer was placed over the dried PU adhesive. The spiral lamination roller was applied again to remove trapped air bubbles. Finally, laminated sheets composed of BOPP/PU/PP and BOPP/PU/PP-lignin were obtained and cured at room temperature for seven days. After curing, the laminates were cut into samples with dimensions of $2.54 \times 10 \mathrm{~cm}$ for peeling tests.

\section{T-Peel Test}

The average peel strength of BOPP/PU/PP and BOPP/PU/PP-lignin laminates was evaluated by the T-peel test using Instron 3369 universal testing. The peel tests were performed by pulling a 50-mm length of the PP from the BOPP film at an angle of $90^{\circ}$ between the films and the direction of applied force, according to the ASTM Standard F904-98(2008) method. The tests were carried out at a crosshead speed of $0.280 \mathrm{~m} / \mathrm{min}$ at room temperature. Five specimens were tested for each condition.

\section{Results and Discussion}

\subsection{Lignins Modification}

\subsubsection{FTI-ATR}

FTIR spectra of KL, M-oxy-KL, and A-oxy-KL are shown in Figure 2 and were normalized with respect to the peak at $1514 \mathrm{~cm}^{-1}(\mathrm{C}=\mathrm{C}$ aromatic vibration) [20]. Comparing the spectra, some remarkable differences confirmed the successful KL hydroxypropylation: (i) the increase in the peak intensities and the emergence of new peaks in the wavenumber region between 3000 and $2800 \mathrm{~cm}^{-1}$, which are related to asymmetric and symmetrical stretching of $\mathrm{CH}_{2}$ and $\mathrm{CH}_{3}$ groups [11]; (ii) the increase in the intensity of the peak around $1370 \mathrm{~cm}^{-1}$, which is associated with the bending of $\mathrm{CH}_{2}$ and $\mathrm{CH}_{3}$ groups [21]; and (iii) the increase in the peak intensity at $1120 \mathrm{~cm}^{-1}$, which is assigned to stretching of $\mathrm{C}-\mathrm{O}$ bonds of the ether groups [22].

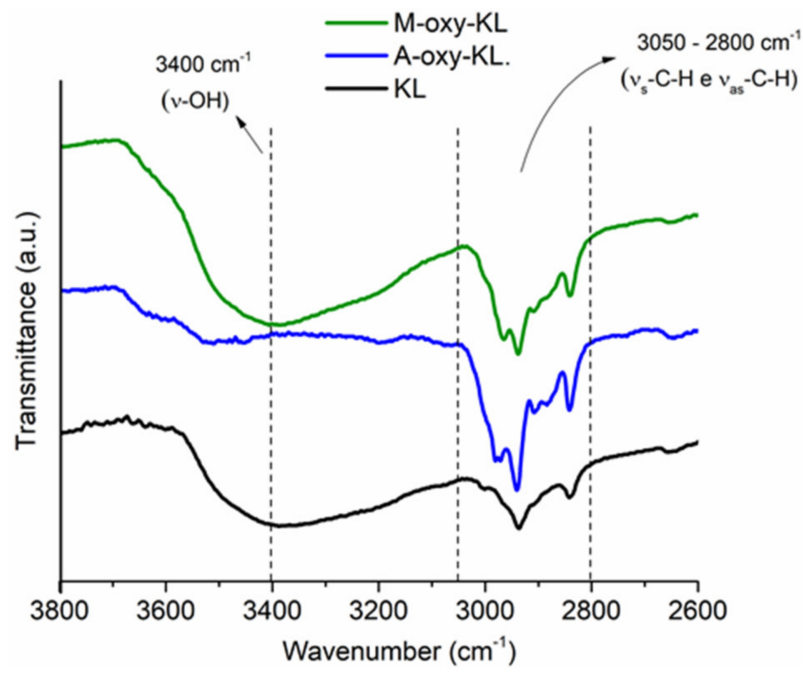

(a)

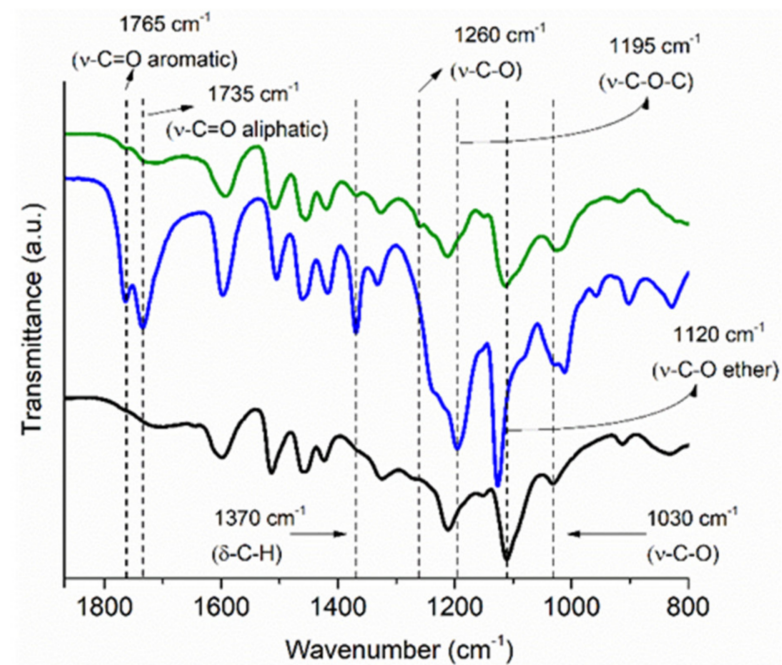

(b)

Figure 2. Fourier-transform infrared (FTIR) spectra of KL, A-oxy-KL and M-oxy-KL. (a) 3800-2600; (b) $1800-800$.

The KL spectrum revealed a broad band centered at $3400 \mathrm{~cm}^{-1}$, assigned to $\mathrm{OH}$ groups stretching [23], which was almost completely consumed after the reaction with 
acetic anhydride, as observed in the A-oxy-KL spectra. Two peaks appeared at 1765 and $1735 \mathrm{~cm}^{-1}$, assigned to carbonyls from aromatic and aliphatic esters groups, respectively [24]. In addition, a strong peak at $1195 \mathrm{~cm}^{-1}$, which is related to the stretching of C-O-C bond in aromatic acetyl groups [25], was only observed in the A-oxy-KL spectra. This evidence confirmed KL acetylation. On the other hand, KL esterification via reaction with maleic anhydride was confirmed by the following evidence observed when KL and M-oxy-KL spectra are compared: (i) the emergence of a weak peak centered at $1765 \mathrm{~cm}^{-1}$ ( $\mathrm{C}=\mathrm{O}$ stretching of aromatic ester); (ii) the increase in the intensity of the peak around $1260 \mathrm{~cm}^{-1}$ and the increase in intensity and width of the peak centered at $1030 \mathrm{~cm}^{-1}$, both associated with the stretching of $\mathrm{C}-\mathrm{O}$ bonds of ester groups [8].

\subsubsection{Lignin Thermal Analysis}

Pristine lignin and its derivatives' thermal behavior was assessed via DSC analysis to confirm the occurrence of chemical modification. Figure 3a shows the heat flow evolution with temperature for the pristine $\mathrm{KL}$ and its derivatives. The glass transition temperature $\left(\mathrm{T}_{\mathrm{g}}\right)$ was assumed as the peak temperature of the derivative of the heat flow (the curves were omitted for the sake of simplicity). The $\mathrm{T}_{\mathrm{g}}$ of $\mathrm{KL}$ was estimated at $170{ }^{\circ} \mathrm{C}$, which agrees with the literature that has reported the $\mathrm{T}_{\mathrm{g}}$ of lignin ranging from $80^{\circ} \mathrm{C}$ to $180{ }^{\circ} \mathrm{C}$, depending on the botanical source and/or extraction method [26]. After chemical modification, there is an evident decrease in $\mathrm{T}_{\mathrm{g}}$ that reaches $105^{\circ} \mathrm{C}$ for A-oxy-KL and $141{ }^{\circ} \mathrm{C}$ for M-oxy-KL. The decrease in the lignin $\mathrm{T}_{\mathrm{g}}$ upon chemical modification was expected and has been demonstrated in several works that employed different reaction routes $[16,20,27-29]$. This trend is mainly explained by two mechanisms. The first one is related to the presence of large lateral groups that increase the molecule's free volume hence decreasing the $T_{g}[30,31]$. The second is associated with the effect of chemical modification on intermolecular interactions. After KL hydroxypropylation, the $-\mathrm{OH}$ moieties are replaced by large $\mathrm{OH}$-terminated aliphatic branches. After further acetylation with acetic anhydride, these hydroxyls are replaced by acetyl groups $\left(-\mathrm{OCH}_{3}\right)$, as evidenced by FTIR-ATR analysis. Clearly, acetyl groups possess a lower polarity that weakens the hydrogen bonding network, which severely impacts lignin macromolecular dynamics and, consequently, its $\mathrm{T}_{\mathrm{g}}[32,33]$. On the other hand, maleic anhydride-modified lignin has a carboxyl ending group that presents an intermediate polarity between $-\mathrm{OH}$ and $-\mathrm{OCH}_{3}$, and therefore, a less pronounced effect on the intermolecular interaction, yielding a more modest decrease of the $T_{g}$ compared to pristine lignin.

The thermograms of KL and chemically modified KL are presented in Figure 3b (left axis). Around $100{ }^{\circ} \mathrm{C}$ there is a small weight loss for all samples (lower than $5 \%$ ) that is attributed to water evaporation and is commonly seen during lignin heating scans. Among the three samples, A-oxy-KL presented the lower weight loss in this stage (Figure $3 \mathrm{~b}$ inserts). This is a consequence of lignin hydrophobization upon acetylation of $-\mathrm{OH}$ moieties in the lignin structure, and a similar effect has been seen elsewhere [34,35]. Around $250{ }^{\circ} \mathrm{C}$ a more abrupt decline in the weight percentage can be seen in all the samples as an indication of the main degradation step that occurs between 250 and $500{ }^{\circ} \mathrm{C}$ and is related to the decomposition of alkyl-ether linkages, dehydration, and decarboxylation reactions $[36,37]$. Lignin chemical modification slightly increased the thermo-resistance compared to pristine lignin. This is mirrored by the lower maximum degradation temperature of the latter $\left(350{ }^{\circ} \mathrm{C}\right)$ in comparison to the chemically modified counterparts $\left(370\right.$ and $380{ }^{\circ} \mathrm{C}$ for Aoxy-KL and M-oxy-KL, respectively), as evidenced by the derivative of the weight loss (Figure $3 b$, right axis). 


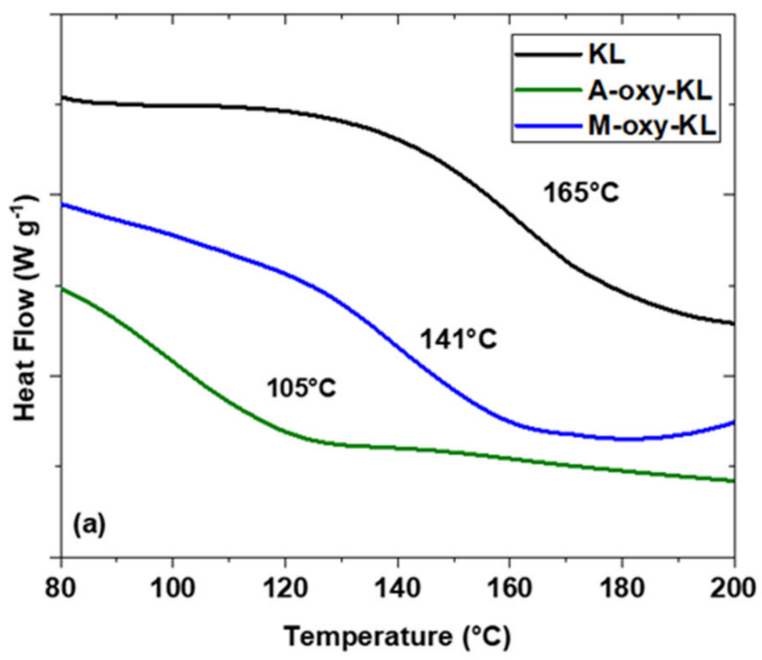

(a)

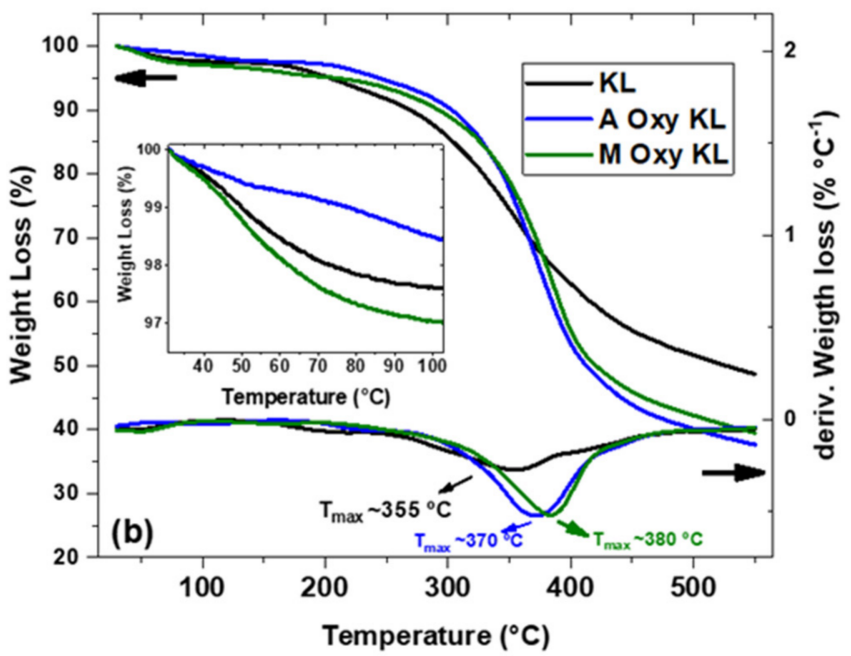

(b)

Figure 3. (a) Heat flow evolution with temperature of pristine lignin (KL) and its derivatives (A-oxyKL and M-oxy-KL) (b) Weight loss (\%) (left axis) and derivative of weight loss (right axis) curves of pristine lignin (KL) and its derivatives (A-oxy-KL and M-oxy-KL). Insert: zoom on the 40 to $100{ }^{\circ} \mathrm{C}$ range to highlight the differences in moisture loss.

The char mass residue at $550{ }^{\circ} \mathrm{C}$ is found to decrease with lignin chemical modification compared to KL. The char residue after lignin pyrolysis is associated with the high thermal resistance of the aromatic backbone in its chemical structure [38,39]. Upon chemical modification by hydroxypropylation followed by acetylation, large aliphatic branches were included in the lignin structure, which reduces the char residue as confirmed in previous works that attempted a similar approach $[40,41]$. Therefore, both thermal analyses provide strong evidence of the successful chemical modification of KL by hydroxypropylation followed by esterification with acetic anhydride and maleic anhydride.

\subsection{Composites Characterization}

\subsubsection{DSC}

DSC analysis was carried out to evaluate the effects of lignin incorporation on the thermal events of the PP matrix. Additionally, these results might also provide some information regarding the composite's microstructure by means of the degree of crystallization $(\chi(\%))$, calculated according to Equation (3). Table 3 summarizes the main thermal events as well the crystallization degrees, while the thermograms are shown in Figure 4.

Table 3. Peak temperatures $\left({ }^{\circ} \mathrm{C}\right)$ of the main thermal events observed during the cooling and second heating scan. The final column shows the crystallinity degree $(\chi \%)$, obtained from the melting peak of the second heating scan.

\begin{tabular}{ccccc}
\hline Sample & $\mathbf{T}_{\mathbf{g}}\left({ }^{\circ} \mathbf{C}\right)$ & $\mathbf{T}_{\mathbf{c}}\left({ }^{\circ} \mathbf{C}\right)$ & $\mathbf{T}_{\mathbf{m}}\left({ }^{\circ} \mathbf{C}\right)$ & $\chi(\mathbf{\%})$ \\
\hline PP & -13.24 & 130.76 & 165.1 & 9.86 \\
PP_KL_1 & -12.94 & 126.53 & 164.1 & 9.73 \\
PP_KL_2.5 & -13.04 & 128.50 & 163.8 & 9.89 \\
PP_KL_5 & -13.13 & 122.91 & 164.6 & 9.59 \\
PP_A_ & -12.35 & 130.86 & 164.2 & 10.16 \\
Oxy_KL_1 & -12.45 & 126.22 & 163.5 & 9.71 \\
PP_A_Oxy_KL_2.5 & -12.15 & 126.22 & 164.0 & 9.96 \\
PP_A_Oxy_KL_5 & -13.13 & 124.10 & 164.2 & 9.54 \\
PP_M_Oxy_KL_1 & -13.04 & 131.81 & 164.3 & 10.02 \\
PP_M_Oxy_KL_2.5 & -12.84 & 126.62 & 164.2 & 9.78 \\
PP_M_Oxy_KL_5 & - & &
\end{tabular}



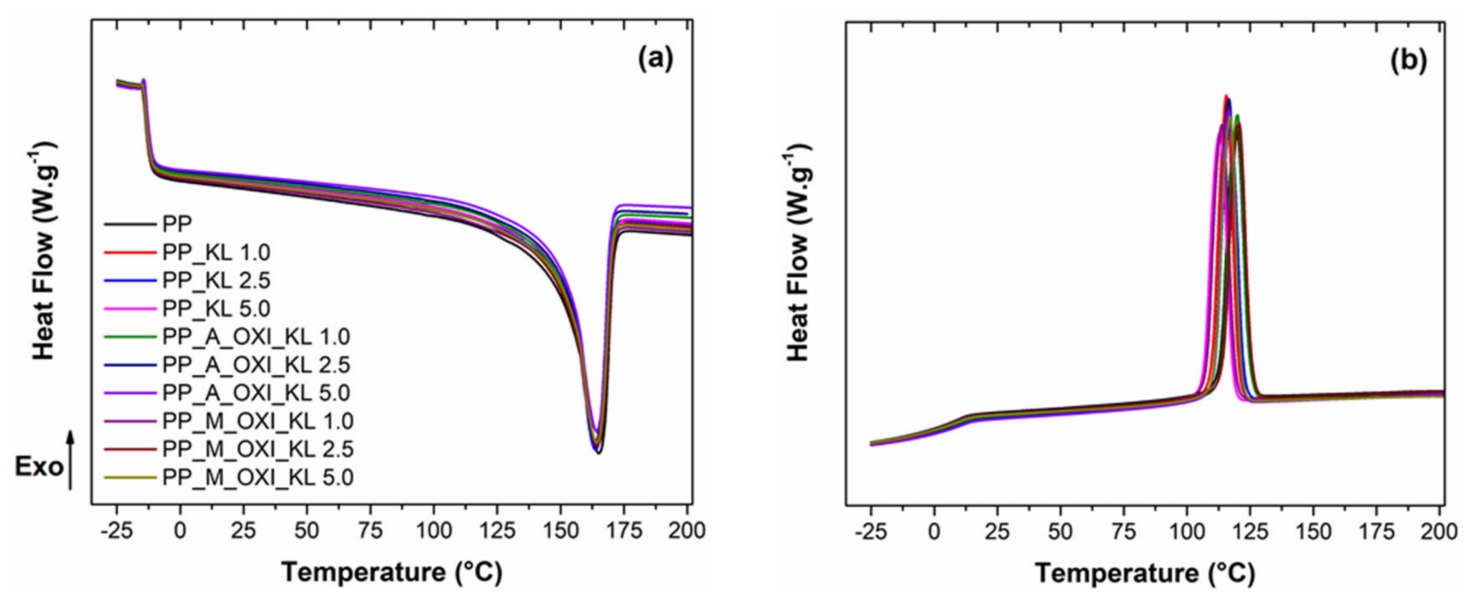

Figure 4. Heat flow evolution with temperature for pristine PP and PP/lignin and its derivative composites during (a) the second heating scan, featuring the glass transition and the melting peak, and (b) the cooling scan, featuring the crystallization peak.

In general, the inclusion of lignin and its derivatives did not significantly affect the $T_{g}$ and $T_{m}$ values and shape when compared to the neat PP. Moreover, no clear signal of the lignin phase $\mathrm{T}_{\mathrm{g}}$ can be seen in any of the thermograms. Although astonishing, similar results have been reported in several works with PP and other polymers [42], including a previous one from our research group [7], and is mainly explained by the stiff lignin molecules that hinder $\mathrm{T}_{\mathrm{g}}$ measurements when blended or diluted in other polymers [43]. Additionally, there is possibly an overlap of the $T_{g}$ of the lignin phase with the large endothermic melting peak of PP that might also impair the observation of the two events.

On the other hand, the crystallization peak observed during the cooling scan shows a dependence on the lignin inclusion. In general, the $\mathrm{T}_{\mathrm{C}}$ slightly decreases, and the crystallization peak width increases with the inclusion of lignin. This tendency might be associated with a slower crystallization process [30,43], due to the overall lower mobility of the PP chains upon lignin inclusion. In spite of the somewhat slower crystallization, the inclusion of lignin did not affect the final crystallization degree, as can be seen in the last column of Table 3. Pristine PP showed a crystallization degree of $9.86 \%$, while the inclusion of lignin and its derivatives causes no meaningful change in this value. This is an interesting result, as it suggests that there is no significant alteration of the morphology of the composites that could impact the adhesion behavior in the peel strength test, which is discussed in Section 3.2.4.

\subsubsection{SEM}

Figure 5 presents the micrographs of pristine PP and PP composites with $5 \mathrm{wt} \%$ of lignin. First, the SEM analysis revealed the overall presence of patterns in the cut crosssection of the KL-containing composite, represented in Figure $5 b$ (white arrows). This pattern is quite similar to lignin shape, previously reported elsewhere in KL micrographs [7], and might be related to KL aggregation or phase separation. It is well known that PP and unmodified Kraft lignin are immiscible due to the different natures of both materials, which results in weak dispersion and, consequently, in a heterogeneous morphology with lignin aggregates dispersed in a continuous PP phase [44]. In the literature, besides PP and KL incompatibility, phase separation is usually reported for composites with higher lignin contents $(>10 \mathrm{wt} \%)[45,46]$. However, the previously reported results were obtained from different types of PP, lignin, or processing. On the other hand, composites here investigated with modified lignin exhibited no patterns, revealing the absence of lignin aggregation and indicating a better interaction between PP and modified lignins. This result reveals that both chemical modifications improved the compatibility between lignin and the PP matrix. Lignin modification enhances its dispersion into PP due to the inclusion of aliphatic branches and the weakening of intermolecular interactions between lignin molecules (as 
discussed in the context with DSC analysis). Furthermore, the weakening of intermolecular interactions decreases the tendency of agglomeration [47]. Therefore, a more homogeneous and uniform morphology is expected.

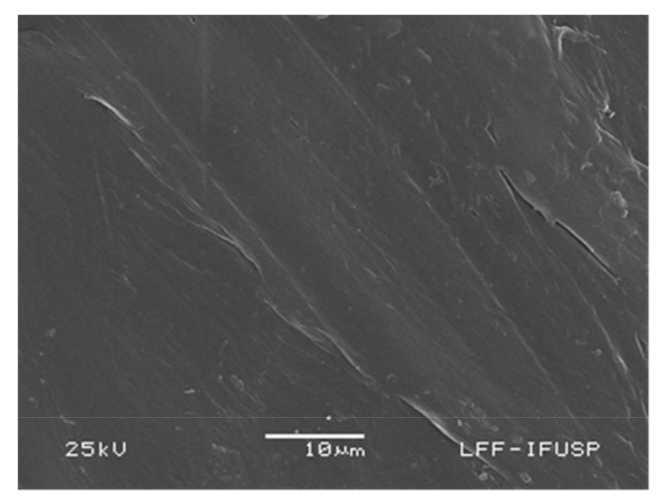

(a)

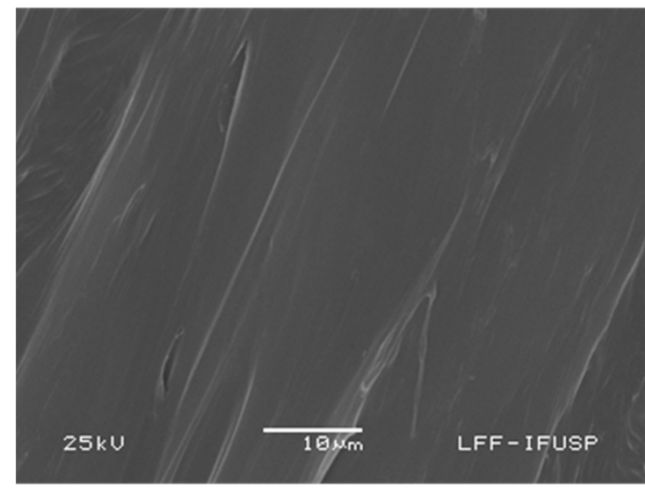

(c)

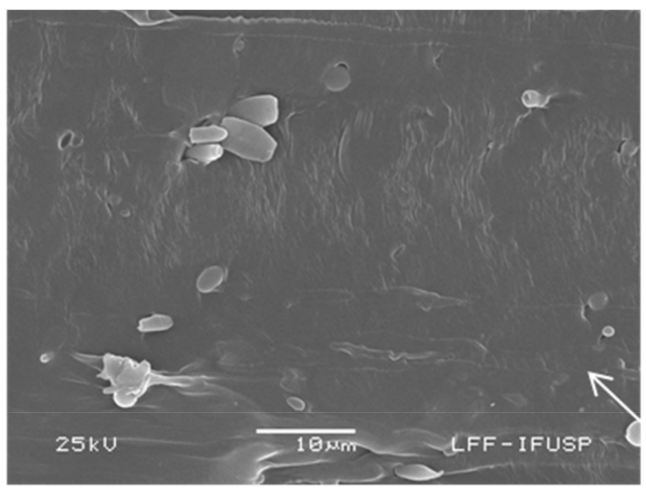

(b)

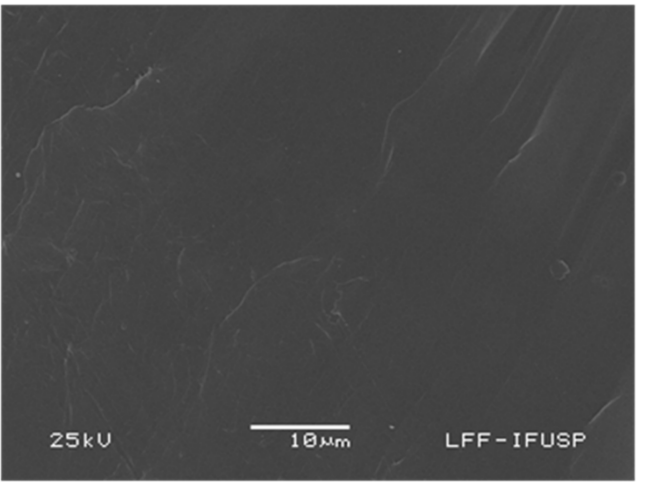

(d)

Figure 5. Cross-section scanning electron micrographs of pristine $\mathrm{PP}$ and $\mathrm{PP}$ composites contaning 5 wt\% of lignin: (a) pristine PP; (b) PP/KL composite; (c) PP/A-Oxy-KL; (d) PP/M-Oxy-KL.

\subsubsection{Surface Energy}

The contact angles obtained for each substrate using either deionized water or diiodomethane are shown in Table 4. The contact angle measured for water on the pristine PP film was significantly higher than those obtained for PP films with any percentage of lignin, even for PP-KL composites, in which agglomeration and poor dispersion of lignin were observed by SEM analysis. This is likely because the added lignin samples have hydroxyl, acetyl, and carboxyl groups that increase the film's overall polarity and thus its hydrophilicity.

The calculated surface energy of neat PP, Figure 6, was 86\% lower than the best result for the PP-lignin composites verified for the composite with $5 \mathrm{wt} \%$ of M_Oxi_KL (54.57 and $108.55 \mathrm{mN} / \mathrm{m}$, respectively). Samples containing $5 \mathrm{wt} \%$ of KL, A-Oxi_KL, and M_Oxi_KL showed an increase of the surface free energy up to $15.7 \%, 11.7 \%$, and $11.0 \%$ in comparison to their $1 \mathrm{wt} \%$ counterparts, respectively. This can be related to the surface wettability in which a higher surface energy value corresponds to a stronger interaction between liquid molecules and the films produced. The best results verified for modified lignin are associated with a better dispersion and compatibility displayed by its respective composites. 
Table 4. Contact angles for water and diiodomethane on PP and PP-lignin films.

\begin{tabular}{ccc}
\hline Sample & Water $\left({ }^{\circ}\right)$ & Diiodomethane $\left(^{\circ}\right)$ \\
\hline PP & $78.17 \pm 0.61$ & $36.87 \pm 1.89$ \\
PP_KL_1 & $66.12 \pm 2.20$ & $30.52 \pm 2.02$ \\
PP_KL_2.5 & $63.25 \pm 1.07$ & $33.82 \pm 0.76$ \\
PP_KL_5 & $60.12 \pm 1.10$ & $38.89 \pm 1.32$ \\
PP_A_Oxi_KL_1 & $63.21 \pm 0.31$ & $30.15 \pm 2.07$ \\
PP_A_Oxi_KL_2.5 & $60.02 \pm 0.80$ & $35.09 \pm 1.87$ \\
PP_A_Oxi_KL_5 & $58.36 \pm 2.01$ & $33.95 \pm 1.02$ \\
PP_M_Oxi_KL_1 & $58.02 \pm 1.87$ & $32.71 \pm 2.89$ \\
PP_M_Oxi_KL_2.5 & $55.89 \pm 2.10$ & $31.64 \pm 2.01$ \\
PP_M_Oxi_KL_5 & $52.61 \pm 2.85$ & $26.78 \pm 2.89$ \\
\hline
\end{tabular}

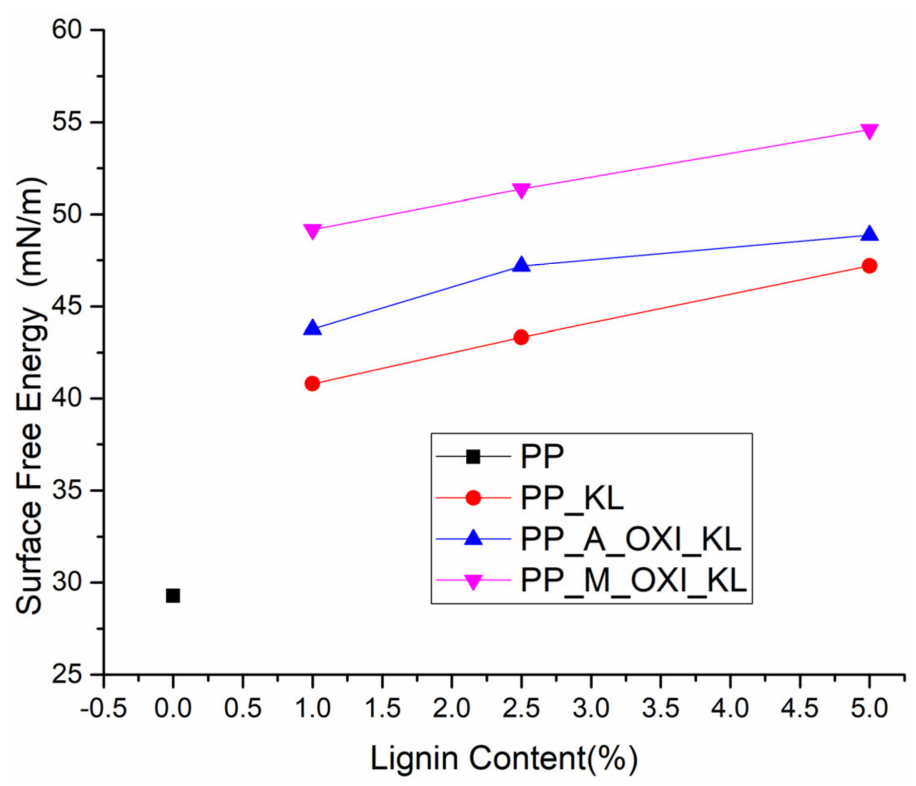

Figure 6. Calculated surface energies of the PP and PP-lignin films. The surface free energy of the PP film without any lignin is represented as a black line for all lignin content $\%$ for comparison purposes.

\subsubsection{T-Peel Test}

The T-peel test results are shown in Table 5. All the samples displayed predominantly adhesive failure. The average peel strength of the laminates increased with the lignin incorporation, regardless of the lignin type. Increased lignin concentration resulted in an improvement of practical adhesion of the laminated BOPP/PP films. These results converge with contact angle measurements since the addition of all types of lignin led to increases in PP surface energy due to the presence of polar groups, especially hydroxyls, in the lignin structure. Since the degree of crystallization of PP was not affected by lignin incorporation, as indicated by DSC results, the improvement in adhesion performance might, in principle, be attributed to this change in surface energies. Surface energy is a critical factor in predicting adhesive joint performance since it is related to the formation of adhesion bonds $[45,48]$. Materials with higher surface energy tend to exhibit stronger attractive forces than those with low surface energy, providing higher wettability, allowing a better spread of the adhesive and, consequently, leading to a higher adhesion. Figure 7 shows the possible adhesion mechanism between PP-lignin composites and PU adhesive that could clarify the improvements in the laminates' average peel strength. This mechanism is based on the formation of hydrogen bonds between the lignin hydroxyl groups and adhesive polar groups. The adhesive failure reinforces the occurrence of this mechanism. 
Table 5. Average peel strength of BOPP/PP and BOPP/PP-Lignin adhesively bonded joints.

\begin{tabular}{cc}
\hline Sample & Average Peel Strength (N/m) \\
\hline PP & $27.20 \pm 0.84$ \\
PP_KL_1 & $28.72 \pm 0.32$ \\
PP_KL_2.5 & $29.15 \pm 0.55$ \\
PP_KL_5 & $30.78 \pm 0.43$ \\
PP_A_Oxi_KL_1 & $35.26 \pm 0.66$ \\
PP_A_Oxi_KL_2.5 & $37.68 \pm 0.91$ \\
PP_A_Oxi_KL_5 & $39.58 \pm 0.13$ \\
PP_M_Oxi_KL_1 & $39.74 \pm 0.89$ \\
PP_M_Oxi_KL_2.5 & $42.80 \pm 1.02$ \\
PP_M_Oxi_KL_5 & $45.15 \pm 1.28$ \\
\hline
\end{tabular}

\section{Hydrogen Bonds}

" Van der Waals Interactions

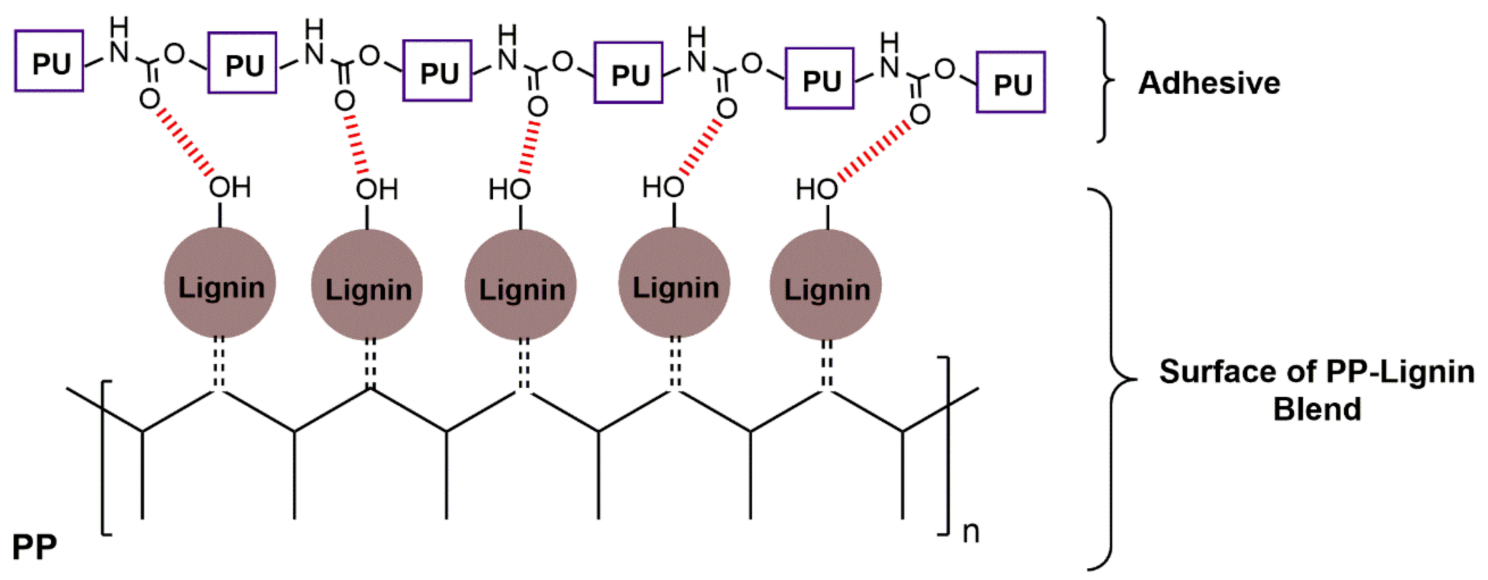

Figure 7. Proposed adhesion mechanism between PP-lignin composites and the adhesive.

Similar results were reported by de Sousa et al. [6], which investigated the effect of the incorporation of unmodified acid (AKL) and basic (BKL) Kraft lignin on the adhesion properties of PPs. The authors verified increases of up to $45 \%$ and $20 \%$ in the PP peel strength compared to a neat PP by the addition of AKL and BKL, respectively. However, unlike observed in the present work, when the BKL content rose, the peel strength gradually decreased. On the other hand, AKL-containing PP composites exhibited a non-linear trend regarding the increase in lignin content.

Among all lignin types, the hydroxypropylated lignin further reacted with maleic anhydride (M_Oxi_KL) provided the highest practical adhesion. Laminates containing PP blended with $5 \mathrm{wt} \%$ of M_Oxi_KL showed a peel strength $66 \%$ higher than neat PP. For the same concentration, the incorporation of unmodified lignin $(\mathrm{KL})$ and hydroxypropylated lignin acetylated (A_Oxi_KL) led to increases of $13 \%$ and $46 \%$ in the peel strength, respectively. Furthermore, laminates containing only $1 \mathrm{wt} \%$ of M_Oxi_KL exhibited higher peel strength than all those containing KL and A_Oxi_KL, even at $5 \mathrm{wt} \%$ loading. The results revealed a positive effect of lignin chemical modification on the practical adhesion of the laminates. This positive effect can be associated with better compatibilization between PP and modified lignin [46,47], confirmed previously by SEM analysis. Consequently, surface and mechanical properties are improved [49,50]. Both properties contributed to the adhesion improvement of PP/lignin composites in BOPP/PU/PP-lignin laminates. Furthermore, in addition to the better compatibility, lignin modification led to an increase 
in molecular mobility (see DSC results), which could make the diffusion of modified lignin to the surface easier, thus improving practical adherence.

\section{Conclusions}

Kraft lignin was chemically modified and further incorporated into PP for surface energy increase. Hydroxypropylation followed by esterification with maleic anhydride and acetylation with acetic anhydride reduced the Kraft lignin $\mathrm{T}_{\mathrm{g}}$ from 165 to $141^{\circ} \mathrm{C}$ and $105^{\circ} \mathrm{C}$, respectively, and improved the compatibility between Kraft lignin and the PP matrix. In general, lignin incorporation did not affect the degree of crystallization and, consequently, the morphology of PP decreased the contact angle of PP composites, and thus increased their surface energy. M_Oxi_KL-containing composites developed higher surface energy compared with their counterpart. The strength of the adhesively bonded joints, or practical adhesion, followed the same trend of energy surface results: lignin addition increased the laminate's practical adhesion, in which M_Oxi_KL-containing composites enhanced the laminate peel strength to $45.15 \mathrm{~N} / \mathrm{m}$, which represents an increase of $66 \%$ in comparison to pristine PP samples. Indeed, Kraft lignin modification emerges as a promising method for the development of a green adhesion promoter.

Author Contributions: Conceptualization, M.P.d.S.B. and D.J.d.S.; methodology, M.P.d.S.B. and D.J.d.S.; software, J.R.G.; validation, M.P.d.S.B., D.J.d.S. and L.D.A.; formal analysis, D.J.d.S. and L.D.A.; Tavares; investigation, M.P.d.S.B.; resources, M.P.d.S.B. and L.D.A.; data curation, J.R.G.; writing — original draft preparation, M.P.d.S.B., J.R.G., L.D.A., L.B.T., N.M.I. and D.J.d.S.; writingreview and editing, M.P.d.S.B., J.R.G., L.D.A., L.B.T., N.M.I. and D.J.d.S.; supervision, D.J.d.S.; project administration, M.P.d.S.B., D.J.d.S. and L.D.A.; funding acquisition, M.P.d.S.B. and L.D.A. All authors have read and agreed to the published version of the manuscript.

Funding: National Counsel of Technological and Scientific Development-CNPq (grant number: 141545/2019-4) and São Paulo Research Foundation-FAPESP (grant number: 2019/05460-6).

Institutional Review Board Statement: Not applicable.

Informed Consent Statement: Not applicable.

Data Availability Statement: The data presented in this study are available on request from the corresponding author.

Acknowledgments: The authors thank the Multiuser Experimental Facilities of UFABC-CEMUFABC for the research structure.

Conflicts of Interest: The authors declare no conflict of interest.

\section{References}

1. Kaymakci, A.; Ayrilmis, N. Surface Roughness and Wettability of Polypropylene Composites Filled with Fast-Growing Biomass: Paulownia Elongata Wood. J. Compos. Mater. 2014, 48, 951-957. [CrossRef]

2. Hernández-Aguirre, O.A.; Núñez-Pineda, A.; Tapia-Tapia, M.; Espinosa, R.M.G. Surface Modification of Polypropylene Membrane Using Biopolymers with Potential Applications for Metal Ion Removal. J. Chem. 2016, 2016. [CrossRef]

3. Xia, Z.; Li, J.; Zhang, J.; Zhang, X.; Zheng, X.; Zhang, J. Processing and Valorization of Cellulose, Lignin and Lignocellulose Using Ionic Liquids. J. Bioresour. Bioprod. 2020, 5, 79-95. [CrossRef]

4. Yu, O.; Kim, K.H. Lignin to Materials: A Focused Review on Recent Novel Lignin Applications. Appl. Sci. 2020, 10, 4626. [CrossRef]

5. Collins, M.N.; Nechifor, M.; Tanasă, F.; Zănoagă, M.; McLoughlin, A.; Stróżyk, M.A.; Culebras, M.; Teacă, C.A. Valorization of Lignin in Polymer and Composite Systems for Advanced Engineering Applications-A Review. Int. J. Biol. Macromol. 2019, 131, 828-849. [CrossRef] [PubMed]

6. Wang, H.M.; Yuan, T.Q.; Song, G.Y.; Sun, R.C. Advanced and Versatile Lignin-Derived Biodegradable Composite Film Materials toward a Sustainable World. Green Chem. 2021, 23, 3790-3817. [CrossRef]

7. De Sousa, R.R.; Gouveia, J.R.; Nacas, A.M.; Tavares, L.B.; Ito, N.M.; de Moura, E.N.; Gaia, F.A.; Pereira, R.F.; dos Santos, D.J. Improvement of Polypropylene Adhesion by Kraft Lignin Incorporation. Mater. Res. 2019, 22. [CrossRef]

8. Pouteau, C.; Dole, P.; Cathala, B.; Averous, L.; Boquillon, N. Antioxidant Properties of Lignin in Polypropylene. Polym. Degrad. Stab. 2003, 81, 9-18. [CrossRef] 
9. Gadioli, R.; Waldman, W.R.; de Paoli, M.A. Lignin as a Green Primary Antioxidant for Polypropylene. J. Appl. Polym. Sci. 2016, 133, 1-7. [CrossRef]

10. Toriz, G.; Denes, F.; Young, R.A. Lignin-Polypropylene Composites. Part 1: Composites from Unmodified Lignin and Polypropylene. Polym. Compos. 2002, 23, 806-813. [CrossRef]

11. Gadioli, R.; Morais, J.A.; Waldman, W.R.; de Paoli, M.A. The Role of Lignin in Polypropylene Composites with Semi-Bleached Cellulose Fibers: Mechanical Properties and Its Activity as Antioxidant. Polym. Degrad. Stab. 2014, 108, 23-34. [CrossRef]

12. Xu, X.; He, Z.; Lu, S.; Guo, D.; Yu, J. Enhanced Thermal and Mechanical Properties of Lignin/Polypropylene Wood-Plastic Composite by Using Flexible Segment-Containing Reactive Compatibilizer. Macromol. Res. 2014, 22, 1084-1089. [CrossRef]

13. Zhang, N.; Li, Z.; Xiao, Y.; Pan, Z.; Jia, P.; Feng, G.; Bao, C.; Zhou, Y.; Hua, L. Lignin-Based Phenolic Resin Modified with Whisker Silicon and Its Application. J. Bioresour. Bioprod. 2020, 5, 67-77. [CrossRef]

14. Li, H.; Liang, Y.; Li, P.; He, C. Conversion of Biomass Lignin to High-Value Polyurethane: A Review. J. Bioresour. Bioprod. 2020, 5 , 163-179. [CrossRef]

15. García, D.E.; Glasser, W.G.; Pizzi, A.; Paczkowski, S.; Laborie, M.-P. Hydroxypropyl Tannin from Pinus Pinaster Bark as Polyol Source in Urethane Chemistry. Eur. Polym. J. 2015, 67, 152-165. [CrossRef]

16. Chen, Y.; Stark, N.M.; Cai, Z.; Frihart, C.R.; Lorenz, L.F.; Ibach, R.E. Chemical Modification of Kraft Lignin: Effect on Chemical and Thermal Properties. BioResources 2014, 9, 5488-5500. [CrossRef]

17. Monteil-Rivera, F.; Paquet, L. Solvent-Free Catalyst-Free Microwave-Assisted Acylation of Lignin. Ind. Crop. Prod. 2015, 65, 446-453. [CrossRef]

18. Brandrup, J.; Immergut, E.H.; Grulke, E.A. (Eds.) Polymer Handbook, 4th ed.; John Wiley \& Sons: New York, NY, USA, 1999.

19. Tavares, L.B.; Ito, N.M.; Salvadori, M.C.; dos Santos, D.J.; Rosa, D.S. PBAT/Kraft Lignin Blend in Flexible Laminated Food Packaging: Peeling Resistance and Thermal Degradability. Polym. Test. 2018, 67, 169-176. [CrossRef]

20. Gouveia, J.R.; Antonino, L.D.; Garcia, G.E.S.; Tavares, L.B.; Santos, A.N.B.; dos Santos, D.J. Kraft Lignin-Containing Polyurethane Adhesives: The Role of Hydroxypropylation on Thermomechanical Properties. J. Adhes. 2021, 97, 1423-1439. [CrossRef]

21. Kühnel, I.; Saake, B.; Lehnen, R. Oxyalkylation of Lignin with Propylene Carbonate: Influence of Reaction Parameters on the Ensuing Bio-Based Polyols. Ind. Crop. Prod. 2017, 101, 75-83. [CrossRef]

22. Duval, A.; Avérous, L. Cyclic Carbonates as Safe and Versatile Etherifying Reagents for the Functionalization of Lignins and Tannins. ACS Sustain. Chem. Eng. 2017, 5, 7334-7343. [CrossRef]

23. Jeong, H.; Park, J.; Kim, S.; Lee, J.; Cho, J.W. Use of Acetylated Softwood Kraft Lignin as Filler in Synthetic Polymers. Fibers Polym. 2012, 13, 1310-1318. [CrossRef]

24. Jeong, H.; Park, J.; Kim, S.; Lee, J.; Ahn, N.; Roh, H. gyoo Preparation and Characterization of Thermoplastic Polyurethanes Using Partially Acetylated Kraft Lignin. Fibers Polym. 2013, 14, 1082-1093. [CrossRef]

25. Gouveia, J.R.; de Sousa Júnior, R.R.; Ribeiro, A.O.; Saraiva, S.A.; dos Santos, D.J. Effect of Soft Segment Molecular Weight and NCO:OH Ratio on Thermomechanical Properties of Lignin-Based Thermoplastic Polyurethane Adhesive. Eur. Polym. J. 2020, 131, 109690. [CrossRef]

26. Fodil Cherif, M.; Trache, D.; Brosse, N.; Benaliouche, F.; Tarchoun, A.F. Comparison of the Physicochemical Properties and Thermal Stability of Organosolv and Kraft Lignins from Hardwood and Softwood Biomass for Their Potential Valorization. Waste Biomass Valorization 2020, 11, 6541-6553. [CrossRef]

27. Saffian, H.A.; Hyun-Joong, K.; Md Tahir, P.; Ibrahim, N.A.; Lee, S.H.; Lee, C.H. Effect of Lignin Modification on Properties of Kenaf core fiber reinforced poly (butylene succinate) biocomposites. Materials 2019, 12, 4043.

28. Laurichesse, S.; Avérous, L. Chemical Modification of Lignins: Towards Biobased Polymers. Prog. Polym. Sci. 2014, 39, 1266-1290. [CrossRef]

29. Laurichesse, S.; Huillet, C.; Avérous, L. Original Polyols Based on Organosolv Lignin and Fatty Acids: New Bio-Based Building Blocks for Segmented Polyurethane Synthesis. Green Chem. 2014, 16, 3958-3970. [CrossRef]

30. Dehne, L.; Vila, C.; Saake, B.; Schwarz, K.U. Esterification of Kraft Lignin as a Method to Improve Structural and Mechanical Properties of Lignin-Polyethylene Blends. J. Appl. Polym. Sci. 2017, 134, 1-8. [CrossRef]

31. Dehne, L.; Vila Babarro, C.; Saake, B.; Schwarz, K.U. Influence of Lignin Source and Esterification on Properties of LigninPolyethylene Blends. Ind. Crop. Prod. 2016, 86, 320-328. [CrossRef]

32. Glasser, W.G.; Jain, R.K. Lignin Derivatives. Holzforschung 1993, 47, 225-233. [CrossRef]

33. Liu, L.Y.; Hua, Q.; Renneckar, S. A Simple Route to Synthesize Esterified Lignin Derivatives. Green Chem. 2019, $21,3682-3692$. [CrossRef]

34. Gordobil, O.; Robles, E.; Egüés, I.; Labidi, J. Lignin-Ester Derivatives as Novel Thermoplastic Materials. RSC Adv. 2016, 6 , 86909-86917. [CrossRef]

35. Gordobil, O.; Delucis, R.; Egüés, I.; Labidi, J. Kraft Lignin as Filler in PLA to Improve Ductility and Thermal Properties. Ind. Crop. Prod. 2015, 72, 46-53. [CrossRef]

36. Zhang, Y.; Liao, J.; Fang, X.; Bai, F.; Qiao, K.; Wang, L. Renewable High-Performance Polyurethane Bioplastics Derived from Lignin-Poly( $\varepsilon$-Caprolactone). ACS Sustain. Chem. Eng. 2017, 5, 4276-4284. [CrossRef]

37. Brodin, I.; Sjöholm, E.; Gellerstedt, G. The Behavior of Kraft Lignin during Thermal Treatment. J. Anal. Appl. Pyrolysis 2010, 87, 70-77. [CrossRef] 
38. Afifi, A.I.; Hindermann, J.P.; Chornet, E.; Overend, R.P. The Cleavage of the ArylOCH3 Bond Using Anisole as a Model Compound. Fuel 1989, 68, 498-504. [CrossRef]

39. Jia, Z.; Lu, C.; Zhou, P.; Wang, L. Preparation and Characterization of High Boiling Solvent Lignin-Based Polyurethane Film with Lignin as the Only Hydroxyl Group Provider. RSC Adv. 2015, 5, 53949-53955. [CrossRef]

40. Li, T.; Ma, H.; Wu, S.; Yin, Y. Effect of Highly Selective Oxypropylation of Phenolic Hydroxyl Groups on Subsequent Lignin Pyrolysis: Toward the Lignin Valorization. Energy Convers. Manag. 2020, 207, 112551. [CrossRef]

41. Saffar, T.; Bouafif, H.; Braghiroli, F.L.; Magdouli, S.; Langlois, A.; Koubaa, A. Production of Bio-Based Polyol from Oxypropylated Pyrolytic Lignin for Rigid Polyurethane Foam Application. Waste Biomass Valorization 2020, 11, 6411-6427. [CrossRef]

42. Gordobil, O.; Egüés, I.; Llano-Ponte, R.; Labidi, J. Physicochemical Properties of PLA Lignin Blends. Polym. Degrad. Stab. 2014, 108, 330-338. [CrossRef]

43. Kun, D.; Pukánszky, B. Polymer/Lignin Blends: Interactions, Properties, Applications. Eur. Polym. J. 2017, 93, 618-641. [CrossRef]

44. Pouteau, C.; Baumberger, S.; Cathala, B.; Dole, P. Lignin-Polymer Blends: Evaluation of Compatibility by Image Analysis. C. R. Biol. 2004, 327, 935-943. [CrossRef] [PubMed]

45. Bozsódi, B.; Romhányi, V.; Pataki, P.; Kun, D.; Renner, K.; Pukánszky, B. Modification of Interactions in Polypropylene/Lignosulfonate Blends. Mater. Des. 2016, 103, 32-39. [CrossRef]

46. Chen, F.; Dai, H.; Dong, X.; Yang, J.; Zhong, M. Physical Properties of Lignin-based Polypropylene Blends. Polymer Compos. 2011, 32, 1019-1025. [CrossRef]

47. Szycher, M. Structure-property relations in polyurethanes. In Szycher's Handbook of Polyurethanes, 2nd ed.; CRC Press: Boca Raton, FL, USA, 2012; pp. 37-86.

48. Packham, D.E. Surface Energy, Surface Topography and Adhesion. Int. J. Adhes. Adhes. 2003, 23, 437-448. [CrossRef]

49. Nacas, A.M.; Vidotti, S.E.; Chinellato, A.C.; dos Santos, D.J. The Role of Polyol Reaction Catalysts in the Cure Kinetics and Mechanical Behavior of Polyurethane Adhesives. J. Adhes. 2018, 94, 880-892. [CrossRef]

50. Luo, S.; Cao, J.; McDonald, A.G. Esterification of Industrial Lignin and Its Effect on the Resulting Poly(3-Hydroxybutyrate-Co-3Hydroxyvalerate) or Polypropylene Blends. Ind. Crop. Prod. 2017, 97, 281-291. [CrossRef] 